\title{
Pediatrics \& Neonatal Biology Open Access
}

\section{The Long Road to Newborn Survival: Working with Parents, Families and Communities to Reduce Preventable Neonatal Deaths}

\section{Rachel N Musoke*}

Department of Paediatrics \& Child Health, University of Nairobi, Kenya

\section{Review Article \\ Volume 1 Issue 1}

Received Date: July 04, 2016

Published Date: July 28, 2016

*Corresponding author: Rachel N Musoke, Professor of Neonatology, Department of Paediatrics \& Child Health, University of Nairobi, Nairobi, Kenya, PO Box 10676-00202KHN; Email: Rachel.musoke@uonbi.ac.ke

\section{Abstract}

At the close of the millennium development goals it was realised that the neonatal mortality contributed to $44 \%$ of the under 5 mortality so as the world moves forward with the sustainable development goals every effort must be made to reduce neonatal mortality [1,2]. This led to the development of every woman every new born strategy and the action plans to achieve reduction in maternal and newborn mortality [3]. The following review takes the community component of the "Every newborn: an action plan to end preventable deaths" [4] and suggests what can be done to ensure newborn survival.

Keywords: Newborn survival; Good home care; Primary health care; Community participation; Community health workers

\section{Introduction}

Reducing preventable neonatal deaths to $<12 / 1000$ births by 2035 reminds me of the Alma-Ata primary health care declaration "health for all by the year 2000" [5]. Well year 2000 came we celebrated entering the $21^{\text {st }}$ century while many of our vulnerable neonates were not able to celebrate with us. Since there were no specific targets, the neonate missed out in nearly all previous global programmes - the time for him is now. We are all ambitious and excited and hopefully the road will be clear with minimal pot holes, hills or mountains. Our governments have developed strategies and plans based on the "Every newborn: an action plan to end preventable deaths" but the implementation of this plan lies with all of us who are in contact with parents, families and communities [4].
The Alma Ata declaration was centred on taking health care to the community. Can we revisit the past to frame the future in planning for primary health care? In regard to newborn survival, we need to ask ourselves: Can we keep most neonates well and healthy at home by empowering the community/parents? If the answer to this question is yes what can we do? Utilisation of primary health care will go a long way to address this. In Every Newborn action plan to end preventable deaths, "Strategic objective 4: Harness the power of parents, families and communities. One of the key actions for strategic objective 4 is: equip families, including men, with knowledge and capacities to provide good home care" [4]. The suggestions below may help us meet the target 


\section{Pediatrics \& Neonatal Biology Open Access}

\section{Maternal nutrition}

One of the missed opportunity and easily doable suggestions of improving neonatal outcome is maternal nutrition. Ensuring a healthy mother preferably before conception: Maternal nutrition has received very little emphasis in programmes to reduce neonatal deaths yet if the mother had an adequate diet there would be fewer LBW infants/preterms that are likely to die [6]. It is well established that adequate pre-conception folate reduces the occurrence of neural tube defects and possibly congenital heart disease [7]. One may argue that in low and middle income countries congenital defect are not important cause of neonatal mortality but as we reduce other causes they will be. Indeed this is the case in the resource rich countries. So we might as well start considering them in all countries. We have great opportunity to address pre-pregnancy nutrition when mothers come to us either in the family planning clinic or when they bring their babies for immunisation If we do this we can continue this exercise during pregnancy when the mother attends the antenatal clinic. It should also be part of the community based programme. Some cultural practices and food taboos during pregnancy may need to be tackled. Even if there is no effect on the foetus maternal well being is worth it.

\section{Essential newborn care}

We need to empower the parents/communities to keep newborn healthy through promotion of healthy behaviour while discouraging or replacing harmful ones. The new mother (especially the first time mother) is often surrounded by a number of people in the home so even if we teach her at the health facility she may be told otherwise by the community especially the people in her household (partner and grandparents). This is why the community is so important is decision making. Some of the guidelines contained in the $2013 \mathrm{WHO}$ postnatal care of the mother and the newborn [8] may have had low quality evidence partly because we have concentrated at the health facility care with little research at community level.

Initiation and Continued Exclusive Breastfeeding: The protective effect of breast milk is no longer debatable. Rates of initiation of breastfeeding within an hour of birth vary from country to country. This is influenced by hospital practices as well as cultural beliefs. But even mothers, who initiate breastfeeding within an hour, may in addition give something else according to cultural belief. In Kenya we have communities who strongly believe the baby's stomach must be cleansed before initiation of breastfeeding. How do we address this? We have to find innovative ways and partner with the community and discuss alternative to this practice. Let the community suggest and own the change otherwise the practice will continue despite our recommendation. Note that we can measure initiation rates but not what else mother gave and we have little or no idea what and how they could contribute to the early ill health especially sepsis.

Cord care: There are many rituals and beliefs on cord care among the varied communities round the world [9]. However, these can be replaced by safe alternatives. Soofi et al. [10] and Mullany et al. [11] reported reduction of mortality with use of chlorhexidine as part of cord care in rural settings. Chlorhexidine is now the advocated way of cord care though there is still some uncertainty of either a once or multiple applications [12]. Multiple applications as recommended by WHO [8] might prevent use of harmful practices if done once in a health facility does it prevent the mother using something else when she goes home? If it can prevent sepsis, apart from cost, does the number of applications matter?

Recognition of a sick newborn and delay in seeking help: Although we are emphasising health promotion, recognition of a sick neonate is crucial. The danger signs are not quite well known by the community especially the young, first time mothers and they are not taught in the antenatal clinic $[13,14]$. On the other hand when a mother recognises that her baby is not well she may decide to wait and see before going to a health facility or may try cultural remedies $[15,16]$. On top of that the cost of care and lack of transport especially at night can also lead to delay in seeking help. Ideally parents should not wait for appearance of danger signs as these signify impending death if the baby is not treated immediately. Though it may be difficult in the first 24-48 hours of birth, but a mother generally knows her baby fairly well and she should be encouraged to consult as soon as possible any time she thinks her baby is not well.

Health education at the health facility: All mothers should be given the knowledge on how to look after themselves and the baby preferably starting in the antenatal clinic. When parents are given adequate and correct information their demand for services increases and this will encourage them come early to the health facility. Kenya has a very informative mother and child booklet that has all the information the parents need including what and how the mother's partner can help 


\section{Pediatrics \& Neonatal Biology Open Access}

[17]. But the few studies did reveal that it is underutilised by both the health care providers and the mothers [18].

Community mobilisation: Men, women, parents, and grandparents together with community leaders (men and women) all have to wake up and take charge. Recognise that neonatal death is unacceptable. If the community owns the programme the chance of sustainability is high. Involvement of men from the start is very important as at nearly all levels they are the primary decision makers. When one enters a community seek them out first - let them know that you will work with them for the betterment of the community [19]. Community mobilisation can involve teachers, religious leaders, any other existing organisation as well as community based health workers.

Utilisation of community health workers (CHW)/volunteers: This is a very important component of primary care system and has been successful in many settings [20-23]. In some countries they are fully recognised and paid by the government [24] and this is what it should be. However in some countries they are just volunteers. The work they do is enormous as they address all aspects of health. If they have to look for their livelihood, devotion to health care promotion may be compromised. Training of these cadres of health care provider is important. If trained and recognised by the community parents can also consult this person rather than waiting to be visited. This system will of course work well if the CHW is supervised by a qualified health professional as well as good link with a health facility $[25,26]$. Operational plan is well explained in the "One Million Community Health Workers: technical task force report" [27]. Most women who deliver at health facilities are often discharged within 24 hours of delivery so home review is important. Since most of the deaths occur in the first week it has been recommended that all new mothers whether delivered at a health facility or home should be visited at least 3 times in the first week of delivery (2448hrs, days 3 \& 7) [8,28,26]. This review can easily be done by a community based health worker.

\section{Conclusion}

Community participation is crucial for the reduction of preventable causes of neonatal mortality. There are effective ways of training and improving knowledge and practices in the community. Time has come for the trained health care providers who are based at health facilities to extend their care beyond the facility. The most feasible way of doing this is through utilisation with supervision of community health workers. Continued research is needed to improve evidence

\section{References}

1. Inter-agency Group for Child Mortality Estimation. Levels and trends in child mortality Report 2015.

2. UNICEF (2015) Committing to child survival: A promise renewed Progress Report.

3. Chou D, Daelmans B, Jolivet RR, Kinney M, Say L (2015) Ending preventable maternal and newborn mortality and stillbirths: Effective interventions and strategies. BMJ 35(1): 351: h4255.

4. WHO, UNICEF (2014) Every newborn: An action plan to end preventable deaths, World health organisation, Geneva.

5. WHO (1978), Declaration of Alma-Ata.

6. Gresham E, Bisquera A, Byles EJ, Hure AJ (2016) Effects of dietary interventions on pregnancy outcomes: a systematic review and meta-analysis. Maternal and Child Nutrition 12(1): 5-23.

7. Czeizel AE, Dudás I, Vereczkey A, Bánhidy F, Folate (2013) Deficiency and Folic Acid Supplementation: The Prevention of Neural-Tube Defects and Congenital Heart Defects. Nutrients 5(11): 47604775.

8. WHO recommendations on postnatal care of the mother and newborn 2013.

9. Obimbo E, Musoke RN, Were F (1999) Knowledge attitudes and practices of mothers and knowledge of health workers regarding care of the newborn umbilical cord. East Afr Med J 76(8): 425-429.

10. Soofi S, Coulsen S, Imdad A, Bhutto N, Ali N, et al. (2012) Topical application of chlorhexidine to neonatal umbilical cords for prevention of omphlitis and neonatal mortality in a rural district of Pakistan: a community based cluster randomised trial. The Lancet 379(9820): 1029-1036.

11. Mullany LC, Darmstadt GL, Khatry SK, Katz J, LeClerq SC, et al. (2006) Topical applications of chlorhexidine to the umbilical cord for prevention of omphalitis and neonatal mortality in southern Nepal: a community- 


\section{Pediatrics \& Neonatal Biology Open Access}

based, cluster-randomised trial. Lancet 367(9514): 910-918.

12. Karumbi J, Mulaku M, Aluvaala J, English M, Opiyo N (2013) Topical umbilical cord care for prevention of infection and neonatal mortality. Pediatric Infect Dis J 32(1): 78-83.

13. Hodgins S, Pradhan YV, Khanal L, Upreti S, Naresh Pratap KC (2013) Chlorhexidine for umbilical cord care: game-changer for newborn survival. Glob Health Sci Pract 1(1): 5-10.

14. Amolo, Lucia (2014) Knowledge and attitude of postnatal mothers on essential newborn care practices at Kenyatta National Hospital. University of Nairobi dissertation.

15. Gathoni A (2014) Mother's knowledge, attitude and practice regarding neonatal illness and assessment of neonates at Kenyatta National Hospital. University of Nairobi dissertation.

16. Amenya Michieka (2014) Care seeking behaviour and knowledge for neonatal illness in Kisii community (Kenya) University of Nairobi dissertation.

17. Waiswa P. Improving Newborn Interventions in SubSaharan Africa - Evaluating the Implementation Context in Uganda. 38037.

18. Kenya Ministry of Health: Mother child booklet 2013.

19. Opondo G (2015) Utilisation of the mother-child health booklet by healthcare workers and caregivers at Mbagathi District Hospital. University of Nairobi dissertation.

20. Gogia S, Sachdev HS (2010) Home visits by community health workers to prevent neonatal deaths in developing countries: a systematic review. Bulletin of the World Health Organization.

21. Shefner-Rogers C (2013) Applied communication for development strategies for newborn care and the prevention and control of pneumonia and diarrhoea. A literature review of the evidence of impact on child survival. UNICEF.
22. Sibley LM, Tesfaye S, Desta BF, Frew AH, Kebede A (2014) Improving maternal and newborn health care delivery in rural Amhara and Oromiya Regions of Ethiopia through the maternal and newborn health in Ethiopia partnership. Journal of Midwifery \&Women's Health 59(S1): S6-S20.

23. Adam MB, Dillmann M, Chen Mk, Mbugua S, Ndung'u J, et al. (2014) Improving Maternal and Newborn Health: Effectiveness of a Community Health Worker Program in Rural Kenya. PLoS One 9(8): e104027.

24. Tripathi A, Kabra SK, Sachdev HPS, Lodha R (2016) Home visits by community health workers to improve identification of serious illness and care seeking in newborns and young infants from low - and middle income countries. Journal of Perinatology 36: S74S82.

25. Nair N, Tripathy P, Prost A, Costello A, Osrin D (2010) Improving Newborn Survival in Low-Income Countries: Community-Based Approaches and Lessons from South Asia. PLoS Med 7(4): e1000246.

26. Sibley LM, Tesfaye S, Desta BF, Frew AH (2014) Improving maternal and newborn health care delivery in rural Amhara and Oromiya regions of Ethiopia through the maternal and newborn health in Ethiopia partnership. J midwifery women's health 59: S6-S20.

27. Earth Institute Columbia University. One Million Community Health Workers: technical task force report.

28. Aboubaker S, Qazi S, Wolfheim C, Oyegoke A, Bahl R (2014) Community health workers: A crucial role in newborn health care and survival. J Glob Health 4(2): 020302 . 